\title{
Bed management team with Kanban web-based application
}

\author{
HERMANO ALEXANDRE LIMA ROCHA ${ }^{1,2}$, ANA KELLY LIMA \\ DA CRUZ SANTOS ${ }^{3}$, ANTÔNIA CELIA DE CASTRO ALCÂNTARA ${ }^{3}$, \\ CARMEN SULINETE SULIANO DA COSTA LIMA ${ }^{3}$, SABRINA GABRIELE \\ MAIA OLIVEIRA ROCHA ${ }^{1}$, ROBERTO MELO CARDOSO ${ }^{3}$, \\ and JAIR RODRIGUES CREMONIN, JR. ${ }^{3}$
}

${ }^{1}$ Community Health Department, Federal University of Ceará, Rua Prof Costa Mendes, 1608, 60.430-130, Fortaleza, Ceará, Brazil, '²ublic Health, Centro Universitário Unichristus, ISEC. R. João Adolfo Gurgel, 133, Cocó, Fortaleza, CE, 60190-060, and ${ }^{3}$ Research Unit Department, Hospital Regional Unimed Fortaleza. Av. Visconde do Rio Branco, 4000—São João do Tauape, Fortaleza—CE, 60055-172, Fortaleza, Ceará, Brazil

Address reprint requests to: Hermano Alexandre Lima Rocha, Universidade Federal do Ceará, Departamento de Saúde Comunitária, Rua Professor Costa Mendes, 1608 ( $5^{\circ}$ andar), Rodolfo Teófilo, Fortaleza-CE, CEP: 60430-140, Brazil. Tel: +55 85 3366-8044, +55 85 98812-8807; Fax: +55 85 3366-8044; E-mail address: hermano@ufc.br, hermanoalexandre@gmail.com

Editorial Decision 20 March 2018; Accepted 29 April 2018

\begin{abstract}
Objective: To measure the effectiveness of the bed management process that uses a web-based application with Kanban methodology to reduce hospitalization time of hospitalized patients.

Design: Before-after study was performed.

Setting: The study was conducted between July 2013 and July 2017, at the Unimed Regional Hospital of Fortaleza, which has 300 beds, of which 60 are in the intensive care unit (ICU). It is accredited by International Society for Quality in Healthcare.

Population: Patients hospitalized in the referred period.

Intervention: Bed management with an application that uses color logic to signal at which stage of high flow the patients meet, in which each patient is interpreted as a card of the classical Kanban theory. It has an automatic user signaling system for process movement, and a system for monitoring and analyzing discharge forecasts.

Main Outcome Measures: Length of hospital stay, number of customer complaints related to bed availability.

Results: After the intervention, the hospital's overall hospital stay time was reduced from 5.6 days to 4.9 days $(P=0.001)$. The units with the greatest reduction were the ICUs, with reduction from 6.0 days to $2.0(P=0.001)$. The relative percentage of complaints regarding bed availability in the hospital fell from $27 \%$ to $0 \%$.

Conclusion: We conclude that the use of an electronic tool based on Kanban methodology and accessed via the web by a bed management team is effective in reducing patients' hospital stay time.
\end{abstract}

Key words: hospital bed capacity, information management, mobile applications, quality improvement, hospital care, statistical process control, access to care 


\section{Background}

Economic performance of a hospital institution can be measured by the excess of a 'typical' patient stay or by the occurrence of long excesses of stay. The duration of hospital admission explains $\sim 85-90 \%$ of hospital cost variation with patients. One more daily in ICU bed, plus the average permanence time expected for a patient, is roughly four times more expensive than the cost of an average hospital daily, and every subsequent daily is about 2.5 times more expensive, cost ratio similar to existing in open units. In a regression model held to explain the expenses of permanence time, patients' clinical characteristics explain only $26 \%$ of the cost variation [1]. In an average length of stay of 4 days, the marginal cost [2] is $\$ 1457$, or $15 \%$ of the total costs, reaching $\$ 1754$ from the fifth day, per extra daily [3].

Currently, the private health system, aiming at a greater competitiveness in the market, and considering population aging, shows a growing concern for better results in healthcare, seeking to increase the volume of patients, reduce hospitalization time and reduce healthcare costs, factors considered necessary for survival in the market. Length of stay is one of the institutional quality indicators used to define the yield and productivity per hospital bed. It is important to note its relevance to health managers, since this indicator evaluates the efficiency of the institution, as well as it can be used to measure the number of hospital beds needed to provide assistance to the population in a specific area, in which the efficiency of use of a bed is increased [4].

Literature shows that patients who receive poor quality of care have significantly longer hospital stay than patients whose care was of acceptable quality in various clinical conditions analyzed [5]. In addition, hospitals that spend relatively less or more than expected with their assistance have significantly longer stay time. The overall pattern of hospital resource allocation was also associated with length of stay. Thus, the measurable clinical effects can be seen as determined by the resource allocation decisions made by hospital management, supporting the need for rigorous decision-making processes [6].

The study of the hospitalization process has received increasing attention, using methodologies developed in the industrial sector, such as Six Sigma, applied to health management, achieving quality improvement with reduced cost in different hospital process [7, 8]. The Kanban methodology, which works with task signaling and prioritization, allows flow to be run as efficiently as possible, and has been successfully implemented in hospital processes [9].

The management of hospital beds by an own staff is essential, and also contributes to reduce the time of treatment of pneumonia, currently a major international focus, responsible for the long stay in most of the institutions of the world. It has been proven that the reduction in the mean stay time of these patients does not cause harm to them [10].

This study aims to measure the effectiveness of the bed management process that uses a web-based tool with the Kanban methodology to reduce hospital stay time. The hypotheses are that this tool can reduce length of stay.

\section{Methods}

\section{Study type}

A before-after study was conducted through the analysis of electronic records of hospital indicators.

\section{Study setting}

The study was carried out with data from the period of July 2013 and July 2017, of the Unimed Regional Hospital of Fortaleza (HRU), a highly complex hospital with 300 beds, of which 60 are in the ICU. It is the largest private hospital in Ceará, northeastern Brazil, which serves all medical specialties. It is an internationally accredited hospital by Qmentum. It has a volume of about 1500 admissions per month. In Brazil, there are two main funding for healthcare, the universal government coverage, SUS and the supplementary health system, mainly funded by employers, that works live an insurance system. The hospital metrics from both systems are not very different [11]. The studied hospital is from the supplementary health system.

\section{Population and sample}

The population was constituted with all adult patients hospitalized at the HRU between July 2013 and July 2017. Data from 67878 patients were analyzed.

\section{Study design}

The intervention of the study was started in August 2015, with the implementation of bed management team and use of the web-based Kanban application for management of time permanence. The application was developed with the graphical interface equivalent to the actual distribution of the beds in each hospital unit. It can be used on mobile and computers, and updates made by users are viewed in real time by other users. The classical Kanban methodology, with the use of cards for the control of the production flow, was adapted in the software to the process of bed management, in the same way of several other processes of market and factory did previously [12], based mainly on the proposal of Decentralized Reactive Kanban, made by Nakamura [13]. The method uses the color logic for the beds (Fig. 1), which signal the stage of the discharge process in which each patient is, thus defining the need for attention and action of the bed management team, according to the priority: if red, the patient should be approached by the team in up to $48 \mathrm{~h}$, if yellow in up to 5 days, and if green in up to 10 days. If no treatment is registered for the patient at these times, the system signals to the team the need for intervention. In addition, it stratifies all patients according to the category of care and issues general daily report or whenever requested. This stratification is carried out based on social risks (for example, absence of family members) and clinical risks (for example, dependence on mechanical ventilation, for example), among others. Finally, it has an automatic user signaling system with emission demand for the managers, in real time, and a system of monitoring and analysis of discharge forecast.

The bed management team consists of a doctor, a nurse and two social workers. When needed the system can suggest a direct contact of one of the team with the professionals directly involved in the assistance, with an estimated personal cost of US\$ 9000.00 per month. The application itself has an approximatively maintenance cost of US\$ 10.00 per month. In case of physicians, the contact is done by the medical doctor of the team. The 24 months prior to implantation were compared with the 24 subsequent months to ensure homogeneity of seasonality.

\section{Variables}

The main variables were: average length of stay, measured by the sum of total patients-day in the period divided by the number of discharges in the period; the hospital occupation in the period, measured as the sum of total patients-day in the period divided by the sum of total number of operational beds-day in the period; and the type of inpatient unit. Also, we identified the number of complaints made by patients in the hospital regarding waiting per bed, obtained through the quality sector of the hospital. 


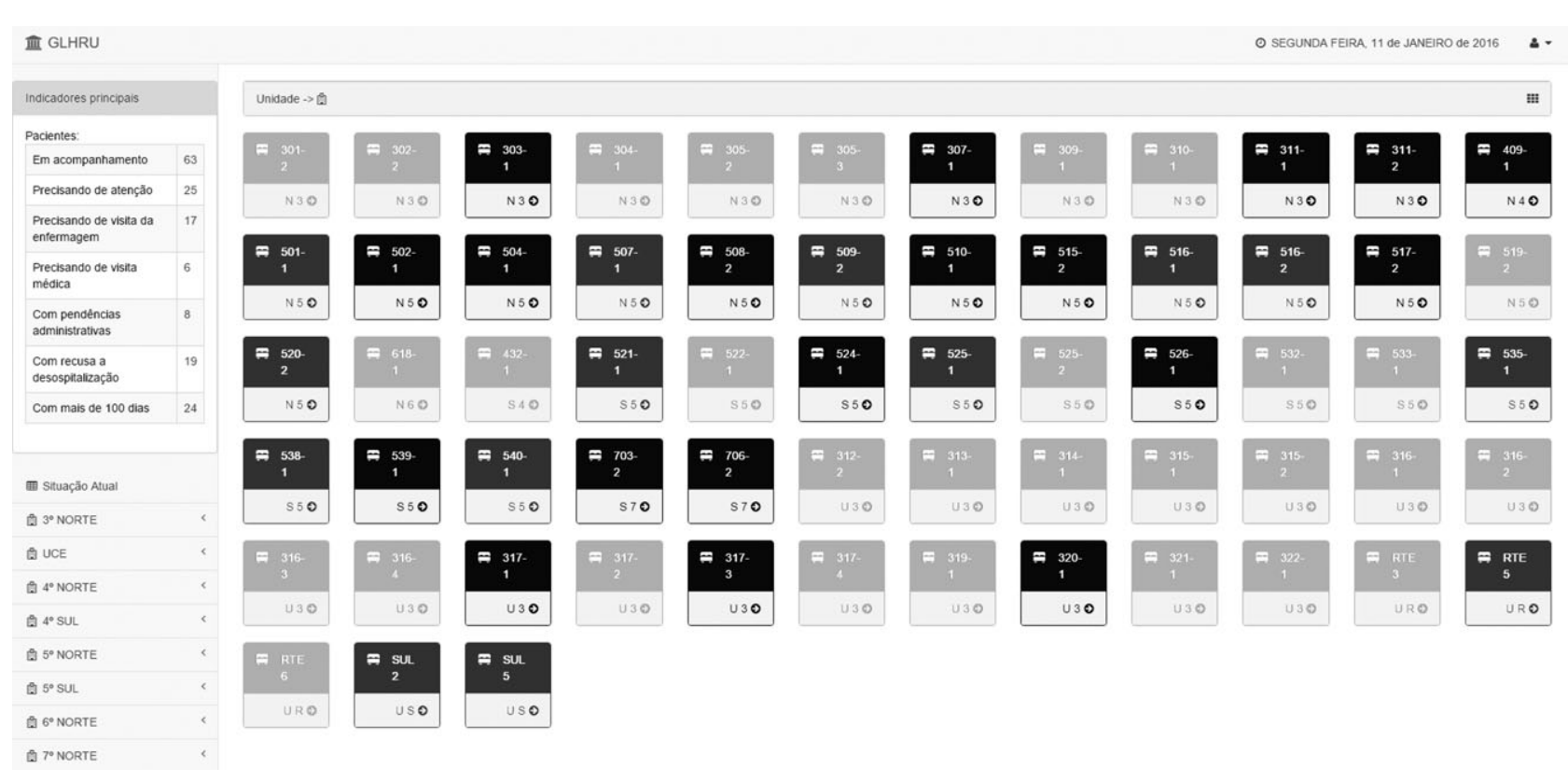

Figure 1 Application main screen, with patient signaling by color, used by bed management team, in HRU, Ceará, Brazil.

\section{Data collect}

The data were collected from the electronic system of indicators and business intelligence of the Hospital, the MV PEP ${ }^{\circledR}$ and through satisfaction surveys conducted by the quality assessment sector.

\section{Data analysis}

The data were initially imputed in Excel software, version 2013, Microsoft Inc ${ }^{\circledR}$. Descriptive analyses were performed, with frequency and percentage calculations, means, medians, standard deviations, maximum and minimum values, as appropriate. Generalized linear regressive models were used to calculate effect size, as proposed by Bernal for analysis of interrupted time series in public health, adjusted for seasonality through stratification by months [14], in addition to Student's $t$-tests and ANOVA for comparison of means. The seasonality of the data was analyzed through seasonal decomposition with multivariate modeling and the weight of the moving averages considered equal in all months. Also, process control analyses were performed with three standard deviations of tolerance (three sigma). The level of statistical significance was set at $5 \%$. We used the programs SPSS for Windows, IBM Inc. v23 and Minitab v17 for Windows.

\section{Ethical aspects}

The research was submitted to the Ethics Committee of Christus University Center. All the ethical principles pertinent to Resolution 466/12 of the National Health Council-CSN/Ministério da Saúde do Brasil-MS, which regulates research with human beings, were respected. The project was approved in the Brazil Platform under registry code CAAE 55700516.8.0000.5049.

\section{Results}

In Table 1, it can be verified, through a simple bivariate comparison, that the reduction between the mean time of hospitalization before and after intervention, considering all hospital beds, was $\sim 0.6$ days, $P$-value $<0.001$. Even more representative reductions were observed when considering only open units and intensive units, both of which were also statistically significant, $P$-value $<0.001$. Also, it is verified that the bed occupancy rate varied positively in the period, increasing one percentage point, although without significance, demonstrating that this indicator was not affected. In the analysis by months, it is noticed that the hospitalization times, considering all the units of the hospital, are higher in the first months of the year, denoting a pattern of seasonality.

The analysis of the temporal variation with seasonal decomposition allowed the identification of seasonal pattern, with an increase in the average stay time in the first semester, coinciding with the rainy season in Brazil. It is also observed a fall in the seasonal trend cycle (Fig. 2).

Figure 3 shows the drop in dwell time graphically, where the shaded area represents the post-intervention period. It can be seen from the regression model that this drop was statistically significant, even if it was controlled by the duration of the observation and the interaction of the latter with the intervention itself $(P$-value $<0.001)$. The time of observation itself was also determinant, suggesting that the permanence time continues to decrease. As the post-intervention determination coefficient is about ten times greater $(0.034$ before and 0.321 after), this trend of decrease over time is attributed to the post-intervention period, which is also observed in the graph. The mean difference of length of stay before and after was 0.56 (IC $0.40-0.72)$, with a $P$-value of 0.001 .

Figure 4 shows the scatter plots of the mean permanence times with the regression results, considering only the ICUs and only the ward units. It was observed a decrease in the time of permanence, with a stable tendency over time, where only the bed-management intervention with Kanban was determinant in the regression model $(P<0.001)$. In this case, the time of observation was not determinant ( $P$ values of 0.502 and 0.942 , respectively).

Figure 5 shows the graph of control of the general hospital stay times, in two stages, before and after the intervention. A narrowing of post-intervention confidence intervals was observed, demonstrating an increase in the control of the process after the implementation of the intervention. 
Table 1 Length of stay in all units and by sector and months, and hospital occupation rate, HRU, Ceará, Brazil

\begin{tabular}{|c|c|c|c|c|c|}
\hline & \multicolumn{4}{|c|}{ Intervention phase } & \multirow[t]{3}{*}{$P$-value } \\
\hline & \multicolumn{2}{|l|}{ Before } & \multicolumn{2}{|l|}{ After } & \\
\hline & Mean & SD & Mean & SD & \\
\hline Total Length of stay (days) & 5.50 & 0.29 & 4.93 & 0.26 & $<0.001^{*}$ \\
\hline Occupation rate & $82.11 \%$ & $3.95 \%$ & $83.11 \%$ & $3.46 \%$ & 0.357 \\
\hline Length of stay in ICUs (days) & 14.18 & 2.67 & 9.40 & 2.02 & $<0.001$ \\
\hline Length of stay in wards (days) & 15.02 & 2.20 & 13.17 & 2.31 & $<0.001$ \\
\hline \multicolumn{6}{|l|}{ Length of stay per month (days) } \\
\hline January & 5.59 & 0.16 & 4.97 & 0.22 & \\
\hline February & 5.21 & 0.33 & 4.95 & 0.27 & \\
\hline March & 5.92 & 0.18 & 4.83 & 0.09 & \\
\hline April & 5.55 & 0.03 & 5.11 & 0.09 & \\
\hline May & 5.85 & 0.09 & 5.15 & 0.26 & \\
\hline June & 5.59 & 0.17 & 4.69 & 0.21 & \\
\hline July & 5.18 & 0.31 & 4.50 & 0.48 & \\
\hline August & 5.50 & 0.03 & 4.94 & 0.20 & \\
\hline September & 5.61 & 0.13 & 5.01 & 0.03 & \\
\hline October & 5.26 & 0.46 & 5.19 & 0.15 & \\
\hline November & 5.38 & 0.00 & 5.16 & 0.04 & \\
\hline December & 5.55 & 0.31 & 4.74 & 0.28 & \\
\hline
\end{tabular}

"Non equal variances considered.
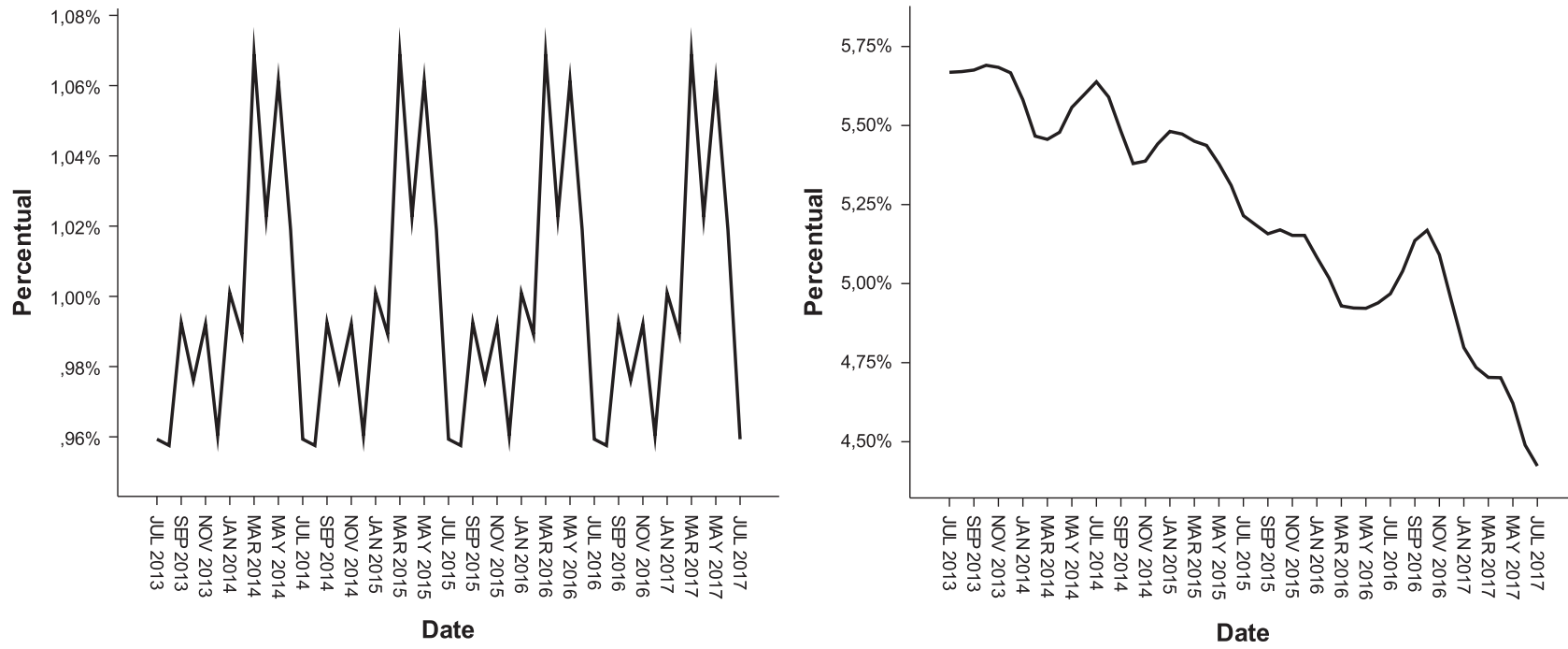

Figure 2 Graph of seasonal factors (left) and trend cycle (right) for mean time of hospital stay, HRU, Ceará, Brazil.

In addition to the results identified in the reduction of length of hospital stay, there was a reduction in customer dissatisfaction. A survey by independent auditors found that the dissatisfaction rate related to waiting for bed by the client was $27 \%$ at the beginning of the project, in August 2015, reaching 0\% in October 2017. Also, hospital infection rates were reduced in the period.

\section{Discussion}

This study verified that bed management performed by a small team in a large hospital aided by an application based on the Kanban methodology is effective in reducing the general length of hospital stay, reducing the length of stay by 0.6 days within 2 years, with potential to achieve even more significant reductions. This application also increases the statistical control of the process.

Considering the marginal cost theory, and a marginal daily cost after the fifth day of US \$ 1754 [3], we have an estimate of hospitalization savings, with a reduction in the length of stay found, of around US $\$ 800$ (average length of hospital stay of 5 days). In a hospital with 1500 admissions per month, this could mean an annual saving of \$ 15786000 .

Seasonality was identified in the behavior of the average length of stay, as expected due to the rainy season in the region that causes an increase in infections and hospitalizations in Ceará, Brazil [15]. Considering the phenomenon found, the analysis was adjusted to compensate the seasonality. 
It was also verified that the hospital occupation increased in the comparison of the evaluated periods, demonstrating that there was an increase in bed rotation, without reducing the occupation of the hospital beds, demonstrating that a balance was found between the patients' waiting for a bed and the time of patients' permanence [16]. This study did not evaluate the impact

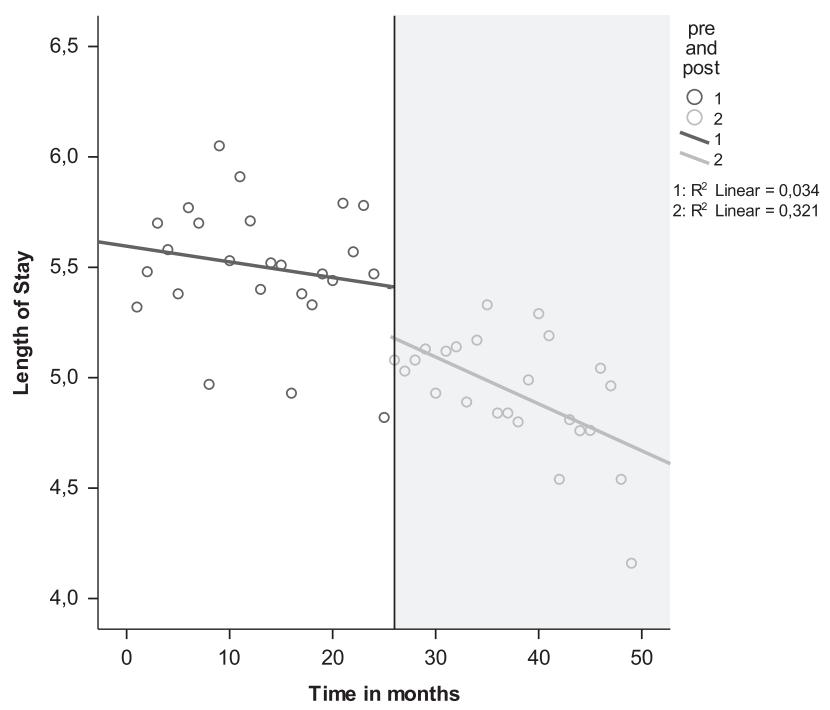

\begin{tabular}{|l|r|}
\hline Model 1 - Dependent Lenght of Stay all Hospital & Adjusted $p$ value \\
\hline Factor Intervention & $<0.001$ \\
\hline Factor Time & 0.001 \\
\hline Interaction factor between intervention and time & 0.393 \\
\hline
\end{tabular}

Figure 3 Length of stay in all hospital pre (blue line) and post (green line) intervention with Kanban web-based application, HRU, Ceará, Brazil.

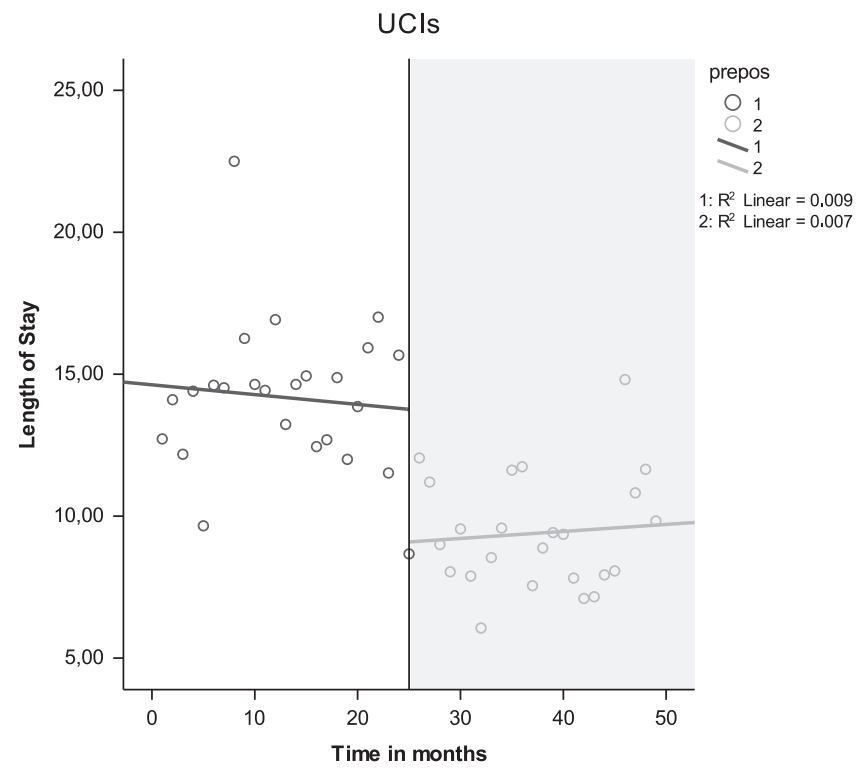

\begin{tabular}{|l|r|}
\hline Model 2 - Dependent Lenght of Stay in UCls & Adjusted $p$ value \\
\hline Factor Intervention & $<0.001$ \\
\hline Factor Time & 0.502 \\
\hline Interaction factor between intervention and time & 0.919 \\
\hline
\end{tabular}

of hospital readmissions, which may interfere with this estimated saving [17].

Several factors may have an impact on patients' length of stay, from their socioeconomic conditions [18] to purely clinical conditions [19-21], thus understanding the need for a multidisciplinary team to deal with the bed management process [22]. In addition, this specific process must be well organized to generate good results [23], and must act quickly so as not to lose the windows of clinical opportunity for discharge presented by patients [22]. Therefore, it is important that a methodology is used to guarantee the fast, continuous and accurate monitoring of this team, through an accessible and practical tool. This work has implemented an electronic system that can easily be accessed via the web in any device (mobile, computer, tablet) that uses the Kanban method. In Brazil, 20\% of the hospitalizations that evolve to long stay are due to socio-familiar problems. Thus, the participation of social workers was fundamental to the success of the project [24].

The Kanban was initially developed for the control of production and flow of materials, being initially thought to solve the problems specifically faced by Toyota [25]. Since then, it has been adapted to improve the effectiveness of several processes, including in the area of health $[12,26]$. This study showed that the use of a tool that automates the signaling of the passages of each patient in the flow of their discharge process, signaled in turn by colors, in which each patient can be interpreted with a card of the original Kanban idea, is effective.

In addition to the direct economic benefit, other benefits are expected with reduced length of stay, such as shorter waiting times for beds leading to reduction of the emergency room queue [27] and reduction of hospital infection rates [28, 29].

In this study, it was not possible to control other possible determinants of the length of stay reduction found. However, other possible biases of quasi-experimental studies were controlled [30].

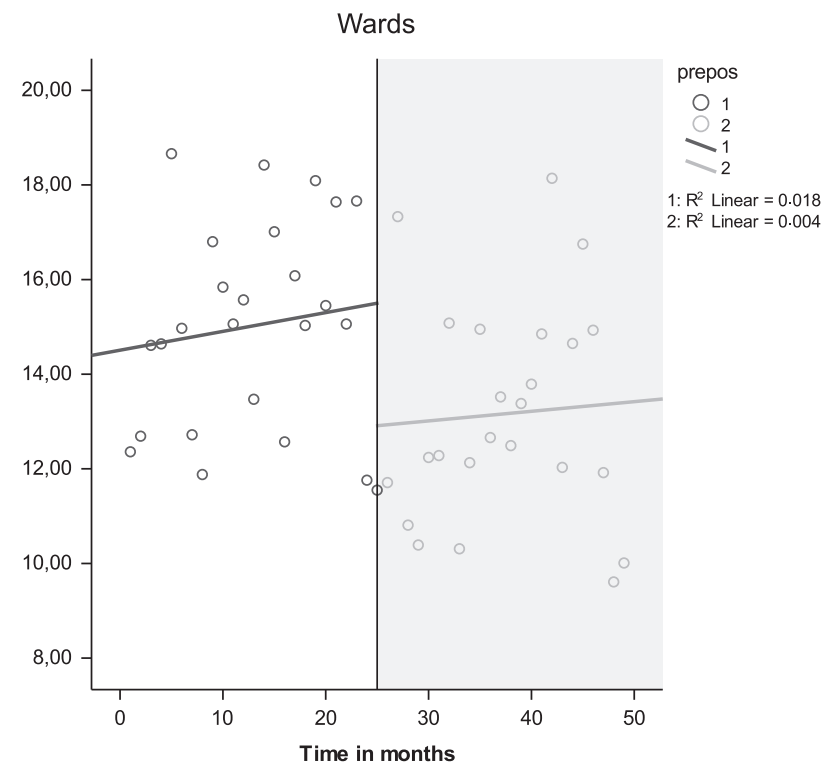

Figure 4 Length of stay in adult $\mathrm{UCl}$ and wards units, pre (blue line) and post (green line) intervention with Kanban web-based application, HRU, Ceará, Brazil. 

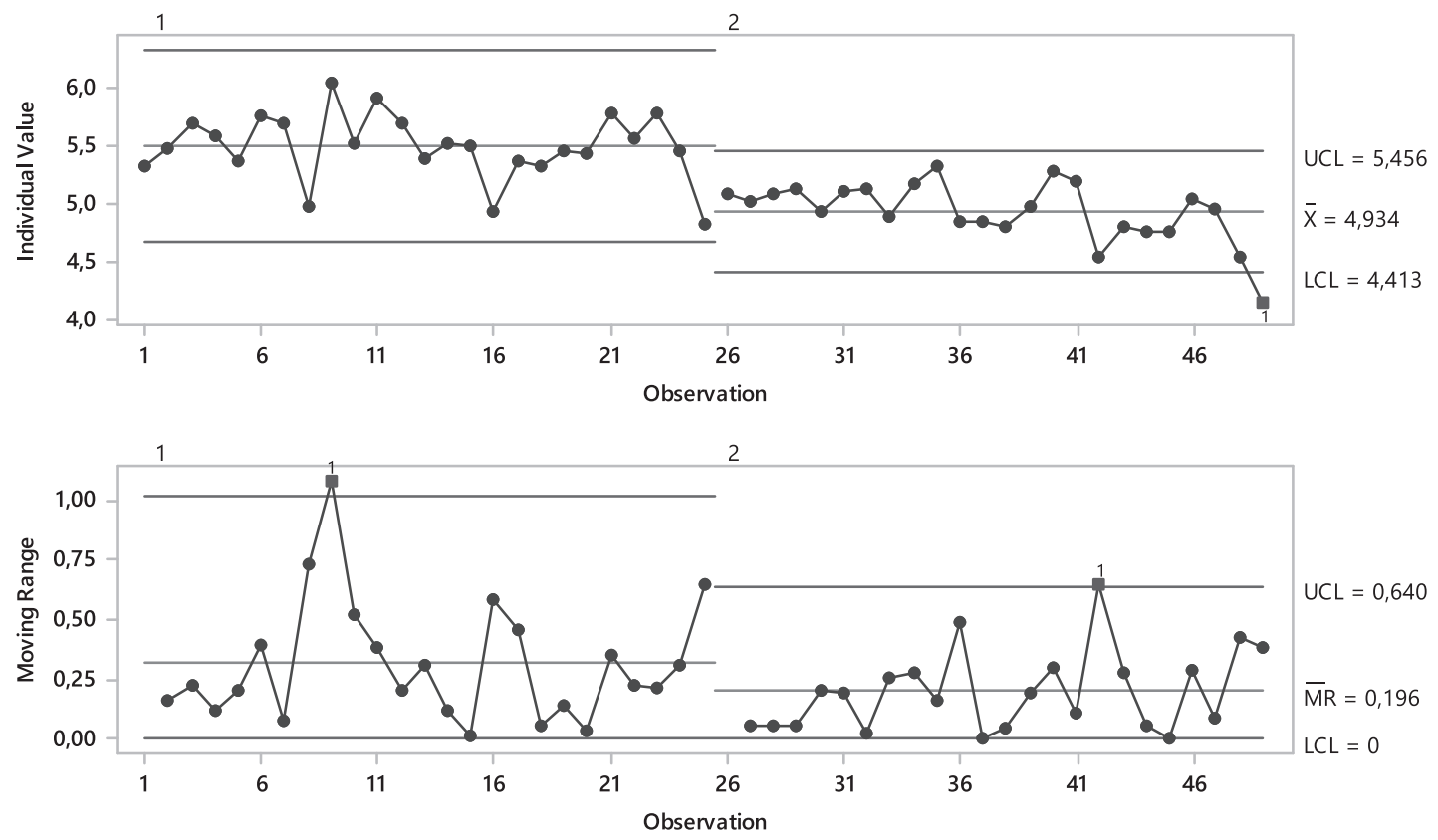

Figure 5 Control chart of Length of Stay by time in two stages, before and after intervention, HRU, Ceará, Brazil.

We conclude that the use of an electronic tool based on Kanban methodology and accessed via the web by a bed management team is effective in reducing patients' hospital stay time.

\section{Funding}

None to report.

\section{Contributor statement}

Author's contribution were as follows: R.H.A.L., S.A.K.L. Da Cruz, A.A.C. De Castro, L.C.S.S. Da Costa have made substantial contributions to conception and design and on revising the manuscript critically for important intellectual content. C.Jr.J.R., C.R.M. and R.S.G.M.O. have made substantial contributions to analysis and interpretation of data and on drafting the article and revising it critically for important intellectual content. All authors read and approved the final version of the manuscript and declare to have no conflicts of interest to disclose.

\section{References}

1. Rapoport J, Teres D, Zhao Y et al. Length of stay data as a Guide to Hospital Economic Performance for ICU patients. Med Care 2003;41:386-97.

2. Drummond MF, Sculpher MJ, Claxton K et al. Methods for the economic evaluation of health care programmes. Oxford: Oxford university press, 2015.

3. Carey K. Hospital length of stay and cost: a multilevel modeling analysis. Health Serv Outcomes Res Methodol 2002;3:41-56.

4. da Silva GS, de Sousa AG, Soares D et al. Evaluation of the length of hospital stay in cases of coronary artery bypass graft by payer. Rev Assoc Med Bras 2013;59:248-53.

5. Thomas JW, Guire KE, Horvat GG. Is patient length of stay related to quality of care? J Healthc Manage 1997;42:489.

6. Needham DM, Anderson G, Pink GH et al. A province-wide study of the association between hospital resource allocation and length of stay. Health Serv Manage Res 2003;16:155-66.

7. Revere L, Black K. Integrating Six Sigma with total quality management: a case example for measuring medication errors. J Healthc Manag 2003;48:377.
8. Van Den Heuvel J, Does RJ, Verver JP. Six Sigma in healthcare: lessons learned from a hospital. Int J Six Sigma Competitive Advantage 2005;1:380-8.

9. Persona A, Battini D, Rafele C. Hospital efficiency management: the justin-time and Kanban technique. International Journal of Healthcare Technology and Management 2008;9:373-91.

10. McCormick D, Fine MJ, Coley CM et al. Variation in length of hospital stay in patients with community-acquired pneumonia: are shorter stays associated with worse medical outcomes? Am J Med 1999;107:5-12.

11. Bittar OJNV. Produtividade em hospitais de acordo com alguns indicadores hospitalares. Revista de Saúde Pública 1996;30:53-60.

12. Lage Junior M, Godinho Filho M. Variations of the kanban system: literature review and classification. Int J Prod Econ 2010;125:13-21.

13. Takahashi K, Nakamura N. Reacting JIT ordering systems to the unstable changes in demand. Int J Prod Res 1999;37:2293-313.

14. Bernal JL, Cummins S, Gasparrini A. Interrupted time series regression for the evaluation of public health interventions: a tutorial. Int J Epidemiol 2017;46:348-55.

15. de Gouvêa CSD, Travassos C, Fernandes C. Produção de serviços e qualidade da assistência hospitalar no Estado do Rio de Janeiro, Brasil-1992 a 1995. Revista de Saúde Pública 1997;31:601-17.

16. Gorunescu F, McClean SI, Millard PH. Correspondence. A queueing model for bed-occupancy management and planning of hospitals. J Oper Res Soc 2002;53:19-24.

17. Carey K. Measuring the Hospital Length of Stay/Readmission Cost Trade-Off Under a Bundled Payment Mechanism. Health Econ 2015;24: 790-802.

18. Epstein AM, Stern RS, Tognetti J et al. The association of patients' socioeconomic characteristics with the Length of Hospital Stay and Hospital Charges within diagnosis-related groups. N Engl J Med 1988;318:1579-85.

19. Pittet D, Tarara D, Wenzel RP. Nosocomial bloodstream infection in critically iii patients: excess length of stay, extra costs, and attributable mortality. JAMA 1994;271:1598-601.

20. Mauldin PD, Salgado CD, Hansen IS et al. Attributable hospital cost and length of stay associated with health care-associated infections caused by antibiotic-resistant gram-negative bacteria. Antimicrob Agents Chemother 2010;54:109-15.

21. Correia MIT, Waitzberg DL. The impact of malnutrition on morbidity, mortality, length of hospital stay and costs evaluated through a multivariate model analysis. Clin Nutr 2003;22:235-9. 
22. Temple M, Dyer P. Doctors, ward rounds, discharge and the interface with the multidisciplinary team. Timely Disch Hosp 2012: 195.

23. Wong H, Wu RC, Tomlinson G et al. How much do operational processes affect hospital inpatient discharge rates? J Public Health (Oxford, England) 2009;31:546-53.

24. Romero DE, Marques A, Barbosa A et al. Internações de idosos por cuidados prolongados em hospitais do SUS no Rio de Janeiro: uma análise de suas características e da fragilidade das redes sociais de cuidado. Camarano AA, organizadora Cuidados de longa duração para população idosa: um novo risco social a ser assumido 2010: 249-78.

25. Sugimori Y, Kusunoki K, Cho F et al. Toyota production system and Kanban system materialization of just-in-time and respect-for-human system. Int J Prod Res 1977;15:553-64.
26. Landry S, Beaulieu M. Achieving lean healthcare by combining the twobin kanban replenishment system with RFID technology. Int J Health Manage Inf 2010;1:85-98.

27. Forster AJ, Stiell I, Wells G et al. The effect of hospital occupancy on emergency department length of stay and patient disposition. Acad Emerg Med 2003;10:127-33.

28. Nguyen-Van-Tam S, Nguyen-Van-Tam J, Myint S et al. Risk factors for hospital-acquired urinary tract infection in a large English teaching hospital: a case-control study. Infection 1999;27:192-7.

29. Hassan M, Tuckman HP, Patrick RH et al. Hospital length of stay and probability of acquiring infection. Int J Pharm Healthc Mark 2010;4:324-38.

30. Harris AD, McGregor JC, Perencevich EN et al. The use and interpretation of quasi-experimental studies in medical informatics. J Am Med Inform Assoc 2006;13:16-23. 